\title{
Restoration of tubular epithelial cells during repair of the postischemic kidney occurs independently of bone marrow-derived stem cells
}

\author{
Jeremy S. Duffield, ${ }^{1}$ Kwon Moo Park, ${ }^{1,2}$ Li-Li Hsiao, ${ }^{1}$ Vicki R. Kelley, ${ }^{1}$ \\ David T. Scadden, ${ }^{3}$ Takaharu Ichimura, ${ }^{1}$ and Joseph V. Bonventre ${ }^{1,4}$
}

\begin{abstract}
${ }^{1}$ Renal Division and Department of Medicine, Brigham \& Women's Hospital and Harvard Medical School, Boston, Massachusetts, USA.
2Department of Anatomy, School of Medicine, Kyungpook National University, Daegu, Republic of Korea. ${ }^{3}$ Center for Regenerative Medicine \& Technology, Massachusetts General Hospital, Harvard Medical School, Charlestown, Massachusetts, USA. ${ }^{4}$ Harvard-Massachusetts Institute of Technology Division of Health Sciences and Technology, Boston and Cambridge, Massachusetts, USA.
\end{abstract}

\begin{abstract}
Ischemia causes kidney tubular cell damage and abnormal renal function. The kidney is capable of morphological restoration of tubules and recovery of function. Recently, it has been suggested that cells repopulating the ischemically injured tubule derive from bone marrow stem cells. We studied kidney repair in chimeric mice expressing GFP or bacterial $\beta$-gal or harboring the male $Y$ chromosome exclusively in bone marrow-derived cells. In GFP chimeras, some interstitial cells but not tubular cells expressed GFP after ischemic injury. More than $\mathbf{9 9} \%$ of those GFP interstitial cells were leukocytes. In female mice with male bone marrow, occasional tubular cells $(\mathbf{0 . 0 6 \% )}$ ) appeared to be positive for the $\mathrm{Y}$ chromosome, but deconvolution microscopy revealed these to be artifactual. In $\beta$-gal chimeras, some tubular cells also appeared to express $\beta$-gal as assessed by $X$-gal staining, but following suppression of endogenous (mammalian) $\beta$-gal, no tubular cells could be found that stained with $\mathrm{X}$-gal after ischemic injury. Whereas there was an absence of bone marrow-derived tubular cells, many tubular cells expressed proliferating cell nuclear antigen, which is reflective of a high proliferative rate of endogenous surviving tubular cells. Upon i.v. injection of bone marrow mesenchymal stromal cells, postischemic functional renal impairment was reduced, but there was no evidence of differentiation of these cells into tubular cells of the kidney. Thus, our data indicate that bone marrow-derived cells do not make a significant contribution to the restoration of epithelial integrity after an ischemic insult. It is likely that intrinsic tubular cell proliferation accounts for functionally significant replenishment of the tubular epithelium after ischemia.
\end{abstract}

\section{Introduction}

Acute renal failure (ARF) is a common disease. Many disparate etiologies, including various nephrotoxins, can lead to ARF via a mechanism involving reduced total or segmental renal blood flow with resultant ischemic injury. The mortality associated with this syndrome is high and has not changed significantly over the last 50 years. To date, there are few therapies of proven benefit in the treatment of active disease or as prophylaxis (1). Ischemia causes changes in tubular cell polarity; loss of integrity of the tubular epithelial barrier, necrotic and apoptotic cell death; loss of both viable and nonviable cells, which lift off the basement membrane; and expression of genes characteristic of the embryonic kidney mesenchyme $(1,2)$. The damaged kidney epithelium, however, in contrast to heart or brain, can be completely restored in structure and function, although repair often does not occur in a timely fashion in humans.

The kidney possesses a remarkable regenerative capacity after acute ischemic and/or toxic injury. This regenerative capacity

Nonstandard abbreviations used: ARF, acute renal failure; BMSC, bone marrow stem cell; EGFP, enhanced GFP; HPF, high-power field; I/R, ischemia/reperfusion; lin-, hematopoietic lineage-negative; MSC, mesenchymal stromal cell; PCNA, proliferating cell nuclear antigen; PFA, paraformaldehyde; PLP, 2\% PFA, 75 mM L-lysine, and $10 \mathrm{mM}$ sodium periodate.

Conflict of interest: The authors have declared that no conflict of interest exists.

Citation for this article: J. Clin. Invest. 115:1743-1755 (2005).

doi:10.1172/JCI22593. manifests itself by proliferation and migration of poorly differentiated cells along the denuded basement membrane of injured tubular segments within a few days after ischemic insult (3). In animal models of repair following ischemic injury, proliferation is observed to be maximal in the straight segment of the proximal tubule located in the outer medulla, where damage is most apparent. The damaged areas of the nephron are repopulated initially by poorly differentiated proliferating cells that have features of epithelial precursors, such as a less well-developed brush border; downregulation of the transcription factor kid-1 (4); and expression of the intermediate filament protein vimentin, which is normally undetectable in the adult proximal tubule epithelium but is expressed in the embryonic metanephric mesenchyme (3). There are several possibilities for the origin of these regenerating epithelial cells: (a) epithelial cells may dedifferentiate, proliferate, then redifferentiate into mature tubular cells, as a survival response to injury; (b) bone marrow stem cells (BMSCs) may home to the injured epithelium, where local cues trigger differentiation; or (c) a population of renal mesenchymal stem cells exists that may replenish the epithelial cell population after injury.

In addition to tubular cell injury, the peritubular vasculature undergoes changes in response to ischemia. These changes range from activation of inflammatory genes, cell swelling, and disruption of endothelial junctions to detachment of live and dead cells from the basement membrane (5). These endothelial changes, 
A
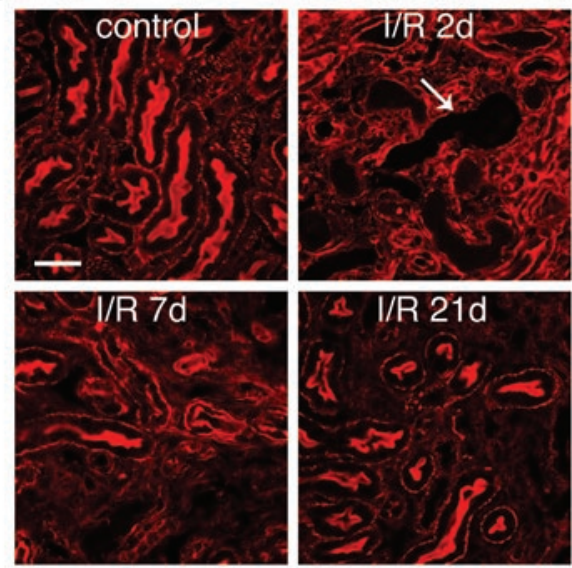

B

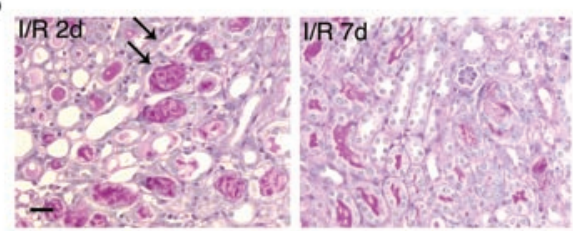

C
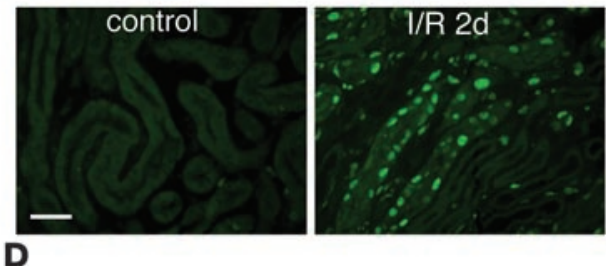

D

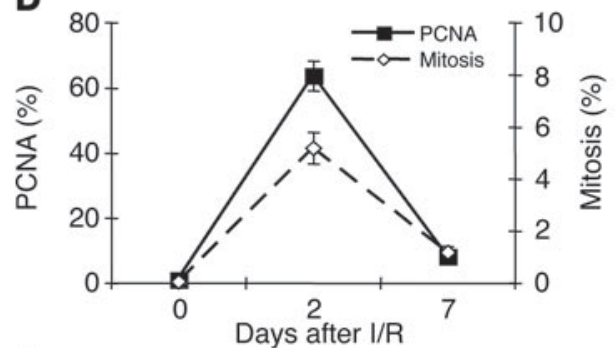

$\mathbf{E}$

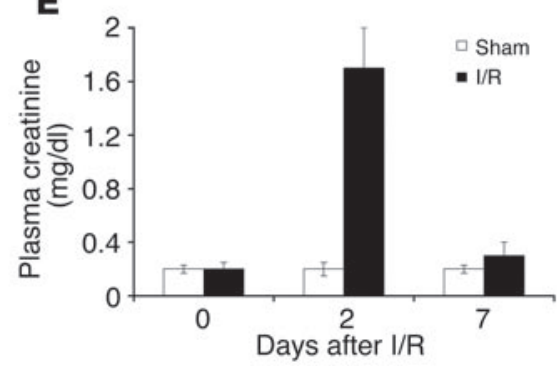

Figure 1

Characterization of I/R injury in chimeric mice. (A) Phalloidin staining of actin cytoskeleton in sham-operated (control) kidneys and at 2, 7, and 21 days following I/R injury. Note the loss of the tubular cell brush border at 2 days and the denuded tubules (arrow) and the progressive restoration with time of both apical actin staining and tubule integrity. (B) PAS-stained sections at 2 and 7 days following I/R injury. Although the necrotic intratubular debris (arrows) is widespread at 2 days, the tubular architecture is significantly restored at 7 days. (C) PCNA staining of tubules in sham-operated (control) and ipsilateral kidney 2 days following I/R injury. (D) Outer medulla intratubular proliferation as assessed by counting mitotic cells in PAS-stained sections and by anti-PCNA immunofluorescence at 0, 2, and 7 days following I/R injury to the kidney. (E) Plasma creatinine levels at 0,2 , and 7 days following bilateral I/R renal injury. Scale bars: $50 \mu \mathrm{m}$.

together with persistent, inappropriate vasoconstriction, lead to reduction of peritubular blood flow, which contributes to extension of the initial ischemic insult (6). Although replacement of the lost tubular cells is essential for nephron regeneration, the return of blood flow, which is dependent upon endothelial cell integrity, is also essential for recovery.

Recently there have been reports of far more plasticity than previously believed in the differentiated state of many different adult cell types. Adult BMSCs, both mesenchymal stromal cells (MSCs) and HSCs, have been reported to have the capacity to differentiate into or fuse with organ-specific cell types (7-12). In 1 study in hepatic tissues, it was concluded that these cells can play an important role in regeneration and repair (13). Several studies claim a role for adult BMSCs in repopulation of tubules of the injured kidney (14-16). One study identified these cells as HSCs (15), another as MSCs (17). Given the poor prognosis of ARF, the promise of stem cell therapy to aid regeneration and organ recovery seems a very attractive approach to disease management.

Using 3 different markers of bone marrow-derived cells in chimeric mice, we now report that following induction of ischemic injury in the mouse, when large numbers of new tubular cells are produced, BMSCs do not localize in the tubules. This indicates that repair of the tubule is a property intrinsic to the kidney itself.
Identification of bone marrow markers in the interstitium, howev$\mathrm{er}$, is indicative of a bone marrow cell origin of not only leukocytes but also a small number of cells lacking the leukocyte common antigen and expressing markers of endothelial cells.

\section{Results}

Ischemic injury results in severe tubular damage followed by repair. Kidney ischemia/reperfusion (I/R) results in disruption of the actin cytoskeleton in damaged tubular cells, which is reversible if the cell survives the insult (3). The actin cytoskeleton was identified by staining with phalloidin conjugated to the cyanine dye Cy3 (phalloidin-Cy3). Two days following unilateral ischemia, there was loss of the brush border of proximal tubular cells of the $\mathrm{S} 3$ segment in the postischemic kidney but not in the contralateral control kidney (Figure 1A). Extensive loss of epithelial cells could be seen in some tubules after ischemia. Seven days following injury, many of the tubules had recovered an apical actin cytoskeletal staining pattern, indicative of restoration of the brush border, and 3 weeks following I/R injury, the lost tubular cells had been almost completely replaced by new cells (Figure 1A).

$\mathrm{I} / \mathrm{R}$ injury resulted in characteristic necrotic and apoptotic changes in the tubules of the outer medulla, followed by intense proliferation and recovery of tubular integrity (Figure 1B) $(3,18)$. In addition 
A
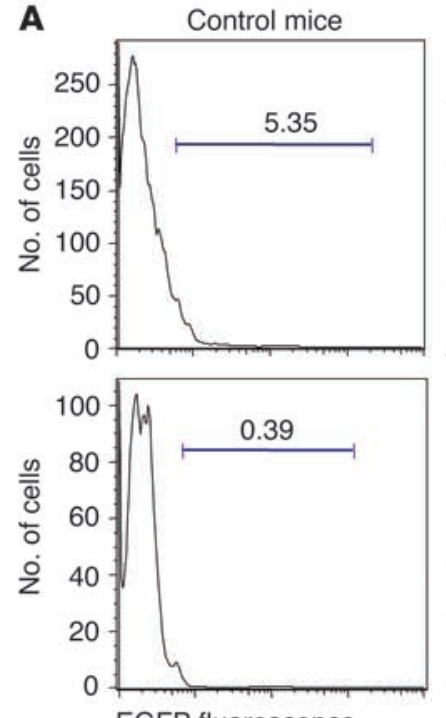

EGFP fluorescence
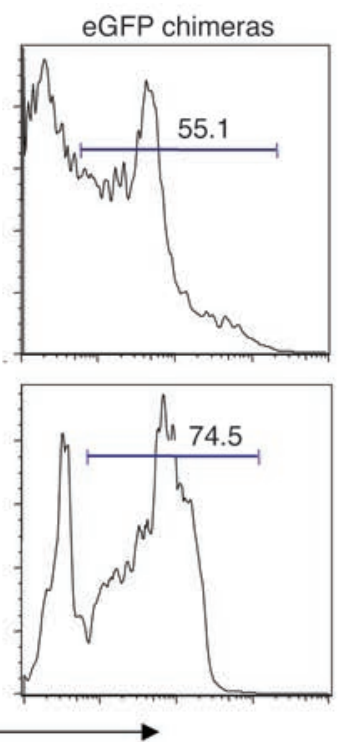

B

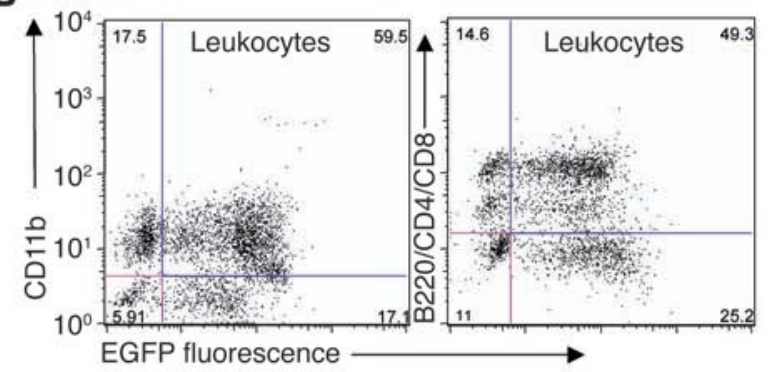

C

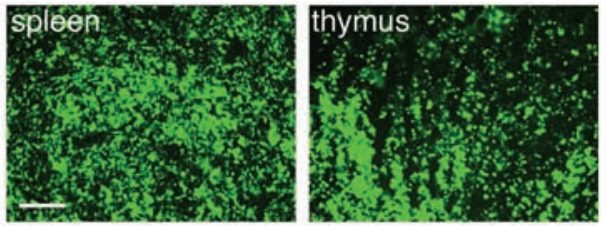

\section{Figure 2}

Confirmation of chimerism in mice transplanted with bone marrow from EGFP-chimeric mice. (A) Top panels: Representative FACS analysis for EGFP fluorescence of bone marrow from wild-type mice (left) and a chimeric mouse at 6 weeks after bone marrow transfer (right). Bottom panels: FACS analysis for EGFP fluorescence of blood leukocytes from wild-type mice (left) and chimeric mice at 6 weeks (right). (B) Representative analysis of leukocytes from EGFP chimeras for EGFP fluorescence and expression of the myeloid lineage marker CD11b (left) or lymphoid lineage markers B220, CD4, and CD8 (right). Note that in each case, the majority of circulating leukocyte populations express EGFP at high levels. (C) Tissue sections of spleen and thymus in chimeric mice showing widespread EGFP fluorescence. Scale bar: $50 \mu \mathrm{m}$.

to identifying mitotic nuclei, we stained sections for nuclei expressing the protein proliferating cell nuclear antigen (PCNA), in order to label and quantify proliferating cells (Figure 1C). Tubular cell proliferation was greatly increased $(63.7 \% \pm 4.7 \%$ PCNA-positive nuclei) in the outer medulla of the recovering kidney compared with the sham-operated control kidney (0 hours) (Figure 1D). Tubular cell proliferation also remained elevated $(8.1 \% \pm 1.3 \%)$ at 7 days. Bilateral ischemic injury resulted in a rise in plasma creatinine levels from baseline of $0.1 \mathrm{mg} / \mathrm{dl}$ to a peak of $1.7 \mathrm{mg} / \mathrm{dl}$ at 48 hours ( $n=4$ per time point), followed by complete recovery to baseline at 7 days (Figure $1 \mathrm{E}$ ).

Enhanced GFP is not detected in tubular cells of enhanced GFP chimeric mice following I/R injury. We generated chimeric mice with donor bone marrow expressing enhanced GFP (EGFP). In the donor, the EGFP gene was driven by the chicken $\beta$-actin promoter and was expressed in all tubular cells (19). I/R injury was induced in male mice 6 weeks following bone marrow transplantation. Bone marrow cells and buffy coat leukocytes in the recipients were analyzed by flow cytometry and compared with cells from the donor mice (Figure 2A). The proportion of bone marrow cells of recipients with increased fluorescence from $\operatorname{EGFP}(57.6 \% \pm 3.1 \%$; $n=12$ ) was comparable to that of donor mice bone marrow cell expression $(59.6 \% \pm 4.2 \% ; n=3)$. The proportion of total blood leukocytes with EGFP fluorescence was somewhat higher in both chimeras and donor mice $(73.5 \% \pm 3.5 \%, n=12$; and $77.4 \% \pm 4.7 \%, n=3$, respectively). The fact that the number of fluorescent cells in bone marrow was not an even higher percentage of total cells likely reflects the previously reported lack of expression of EGFP in cells of the erythroid lineage (19). Myeloid leukocytes $(77.7 \% \pm 3.3 \%)$ and circulating lymphocytes $(74.0 \% \pm 2.5 \%)$ in the chimeras also expressed EGFP, which confirmed that chimerism was not restricted to 1 leukocyte lineage (Figure 2B). In addition, when tissue sections of spleen and thymus from the chimeric mice were analyzed, nearly all cells expressed EGFP (Figure 2C). These data indicate that multipotent hematopoietic stem cell progenitors were transplanted and engrafted into the bone marrow.

In an attempt to detect cells within the tubule that expressed EGFP in these chimeric mice, we examined sections from the ipsilateral and contralateral kidneys of mice at 2 days $(n=4)$ and 7 days $(n=4)$ after ischemia at high power (magnification, $\times 400)$. We found no examples of tubular cells expressing EGFP at these time points (Figure 3). By contrast, analysis of kidney sections from donor EGFP mice confirmed that tubular cells strongly expressed EGFP (Figure 3C), and, therefore, tubular cells in the chimeric mice would be expected to be clearly visible if they were derived from BMSCs from the donor mouse.

Following I/R injury, EGFP is detected in peritubular cells coexpressing leukocyte markers and a small population of cells lacking CD45 and expressing endothelial markers. The postischemic kidneys of EGFP chimeras had an increased number of fluorescent cells (Figure 3B). In order to determine the phenotype of these cells, we immunolabeled tissue sections for leukocyte markers (B220, CD11b, and CD45) and markers of endothelial cells (vWF and CD31), then examined them by confocal microscopy. Not surprisingly, most EGFP-positive cells stained positively for leukocyte markers. Nevertheless, small numbers of EGFP-positive cells $(0.5 \% \pm 0.6 \%)$ did not express the leukocyte common antigen CD45 (Figure 4A) 7 days following I/R injury. In areas, particularly in the outer medulla, where extensive tubule repair had occurred by 7 days following I/R injury, some EGFP cells also expressed CD31, a marker of endothelial cells (Figure 4B). 

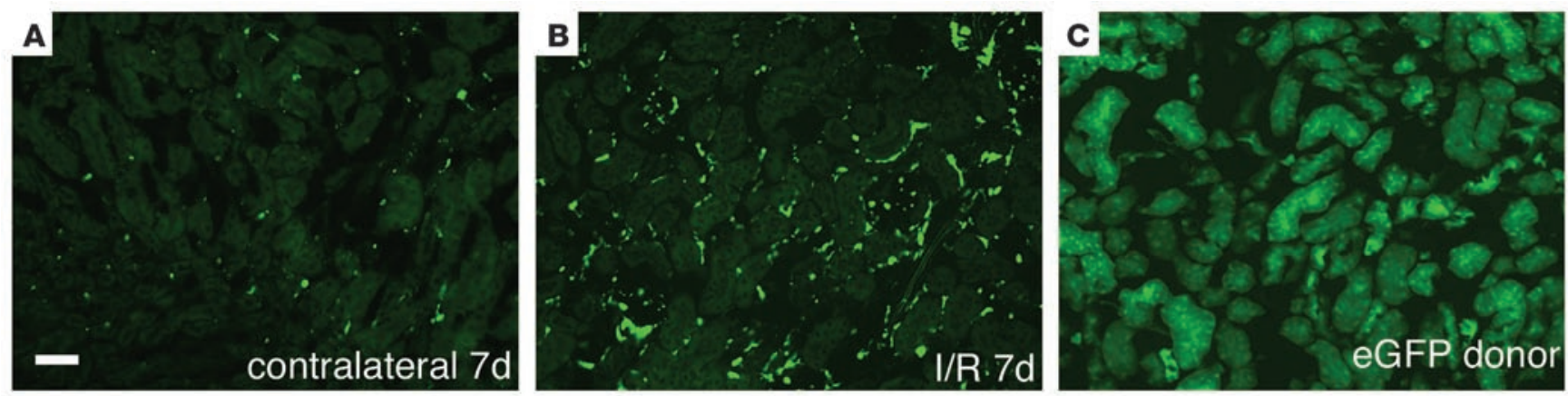

Figure 3

Tubular cells in EGFP chimeras do not express EGFP following I/R injury. Photomicrographs of corticomedullary regions of the contralateral kidney (A) and kidney 7 days after I/R in chimeric mice (B). Note bright EGFP in nontubular cells but only dull autofluorescence in tubular cells. (C) Photomicrograph of kidney from an EGFP donor mouse as positive control showing bright EGFP in tubular cells. Scale bar: $50 \mu \mathrm{m}$.

We examined sections by confocal microscopy to confirm colocalization (Figure 4B). In sections examined by confocal microscopy, vWF, another marker of endothelial cells, was also found to be coexpressed in a small subset of EGFP-positive cells (Figure 4C). EGFP-positive endothelial cells were found only in peritubular capillaries. Neither capillary loops of glomeruli nor arterioles showed any evidence for EGFP positivity. Importantly, in the contralateral kidneys, very few endothelial cells expressing EGFP could be seen (data not shown). In order to determine the proportion of endothelial cells expressing EGFP, serial high-power fields (HPFs) in the cortex were scored for green fluorescent cells that also expressed either vWF or CD31 (Figure 4, B and C). As quantitated in Figure 4D, $0.3 \% \pm 0.3 \%$ of endothelial cells in contralateral kidneys and $1.6 \% \pm 0.4 \%$ in 7 -day postischemic kidneys coexpressed vWF and EGFP. Similar observations were made for CD31-positive cells (Figure 4D). Together, these data suggest that endothelial cell replacement by BMSCs or fusion with bone marrow-derived cells occurs at a low level in response to the vascular injury resulting from ischemia. Sections were also labeled with the fibroblast marker $\alpha$-SMA. Despite an expanded population of $\alpha$-SMA-positive cells, we found no evidence by confocal microscopy for EGFP-expressing fibroblasts in postischemic kidneys (data not shown).

\section{Figure 4}

Bone marrow EGFP-expressing cells lack leukocyte markers and acquire characteristics of peritubular endothelial cells 7 days following I/R injury. (A) Fluorescence images of 7-day postischemic kidney showing interstitial cells expressing GFP but lacking CD45 (red) (arrowhead). T, tubule. (B) Confocal images of 7-day postischemic kidney from EGFP chimeras labeled with anti-CD31 antibodies (red). Note EGFP-positive cells coexpressing CD31 (arrowheads) in the 2D image. Also note that the endothelial cell nucleus expresses EGFP but not CD31, which is not expressed in nuclei (arrows). (C) Confocal images from 7-day postischemic kidney from EGFP chimeras labeled with antibodies against VWF (red). Note EGFP-positive cell coexpressing vWF in cytoplasmic granules (arrowhead) in the 2D image. Also note that the endothelial cell nucleus expresses EGFP but not vWF, which is not expressed in nuclei (arrows). (D) Quantification of bone marrow-derived cells expressing markers of endothelial cells through determination of the number of peritubular cells coexpressing EGFP and endothelial markers in contralateral (control) and 7-day postischemic kidneys. Data are presented as percent of vWF-positive or CD31-positive cells that express EGFP. Scale bars: $50 \mu \mathrm{m}$.
The Y chromosome is found in postischemic kidney peritubular but not tubular cells in sex-mismatched chimeras when assessed by deconvolution microscopy. Female mice with marrow transplants from male mice were subjected to bilateral and unilateral ischemic injury. At both 7 and 15 days after injury, in situ hybridization was used to assess harvested tissue for the presence of Y chromosome-bearing cells. As expected, the majority of cells in the spleen (Figure 5B) and thymus (data not shown) had a nuclear Y chromosome, which confirmed chimerism. In male postischemic kidneys, the Y chromosome was clearly visible by epifluorescent microscopy in $57.6 \% \pm 6.9 \%$ of tubular cells (data not shown).

Postischemic kidneys from 13 chimeric mice were analyzed at days 7 and 15 by in situ hybridization. In each case, chimerism
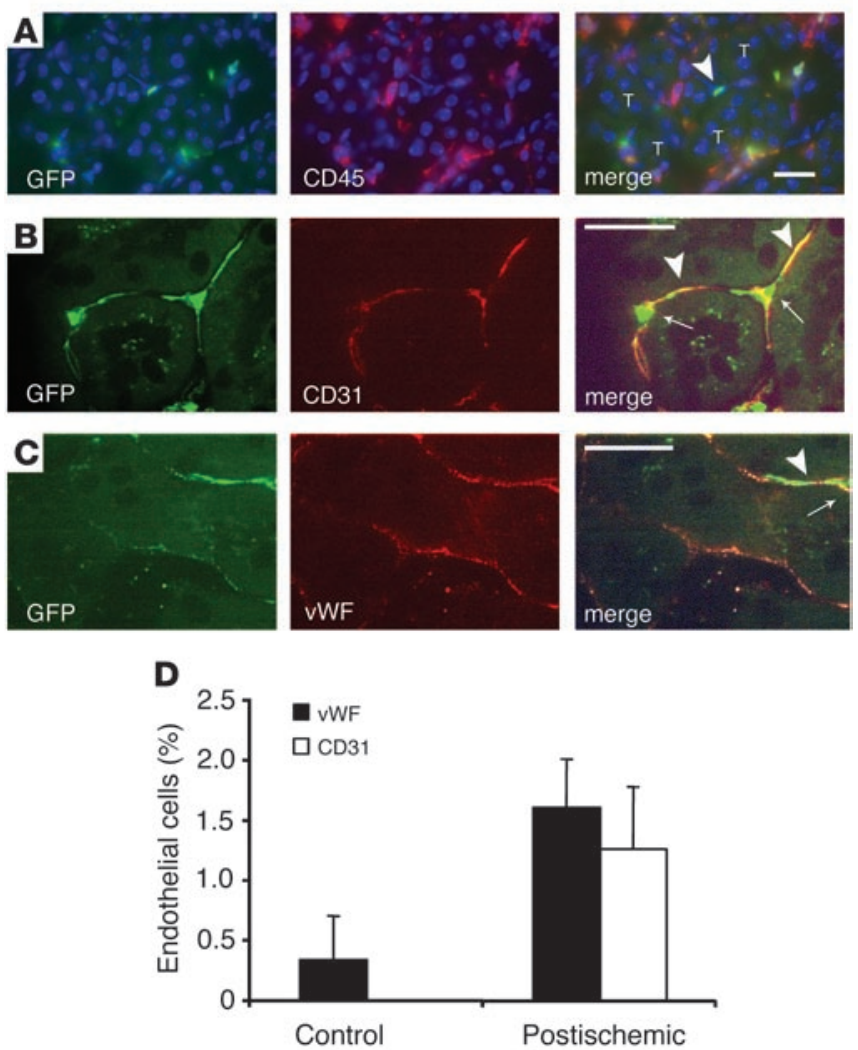

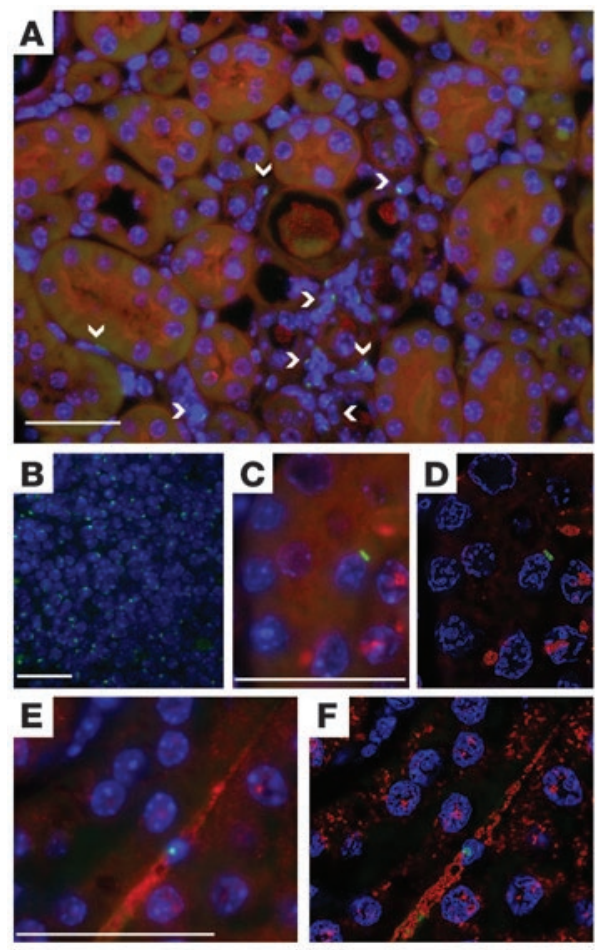

\section{Figure 5}

In female mice with male bone marrow, tubular cells are not derived from bone marrow cells following I/R injury to the kidney. (A) Fluorescent image of kidney outer medulla at day 15 following bilateral ischemic injury. The section was hybridized with an FITC-conjugated probe for the $Y$ chromosome and counterstained with lotus lectin (red) highlighting proximal tubular cells and DAPI showing nuclei. Note that many interstitial cells (arrowheads) exhibit the $Y$ chromosome, but none of the regenerated tubular cells stain for the $Y$ chromosome. (B) Section of spleen showing that the majority of nuclei stain positively for the $Y$ chromosome. (C) Detailed view of a proximal tubule, showing a tubular cell nucleus apparently containing a $Y$ chromosome when viewed by epifluorescence. (D) An ultrathin deconvolution image through the same section as shown in $\mathbf{C}$. The fluorescent label can be clearly seen to reside outside of the nucleus. (E and $\mathbf{F}$ ) Sections hybridized with FITC-conjugated $Y$ chromosome probe were counterstained with antivWF antibodies (red). (E) Peritubular capillary showing endothelial cell nucleus with $Y$ chromosome. (F) Section of the image in $\mathbf{E}$ obtained by deconvolution microscopy confirming VWF staining and a nucleus containing the $Y$ chromosome all in 1 plane. Scale bars: $50 \mu \mathrm{m}$.

was confirmed by simultaneous assessment of hematopoietic organs (Figure 5B). To enhance proximal tubular staining, we also counterstained sections with lotus lectin (Figure 5A). We observed occasional Y chromosome-positive tubular cells in the contralateral, sham-operated, and postischemic kidneys by epifluorescence. The frequency of positive tubular cells in the 15 -day postischemic kidneys was $3.54 \pm 0.59$ per $40 \mathrm{HPFs}$. The frequency was also measured as a percentage of all tubular cells and found to be $0.06 \% \pm 0.01 \%$. This frequency was no different from that of positive tubular cells seen in sham-operated and contralateral kidneys and in kidneys from nonchimeric female mice. The same sections were scrutinized further by deconvolution microscopy. This provided not only exceptional 3D detail of the apparently positive tubular cells, but also a 3D composite for detailed analysis of overlying cells and enhanced ability to determine whether the $\mathrm{Y}$ chromosome was within the confines of the nucleus (Figure 5, C and D). We examined 16 apparently positive tubular cells in postischemic kidneys of chimeric mice and 5 kidneys from female, nonchimeric mice. In all but 1 case, the positive tubular cell was clearly an artifact, due to a rare overlying leukocyte or intratubular monocyte or, most frequently, nonspecific aggregates of fluorescent probe (Figure 5, $\mathrm{C}$ and D). In the 1 example where tubular cell labeling could not be excluded, it was unclear whether this was a leukocyte or a tubular cell. In the 15-day postischemic kidneys, there was only approximately a 2 -fold increase in the level of interstitial leukocytes compared with controls. Since the apparently positive tubule cells were artifacts, sometimes due to leukocytes, one might have expected an increase in the frequency of artifact in postischemic kidneys. However, at such a low frequency, at a time when there was only a 2 -fold increase in the level of interstitial leukocytes, this small increase in leukocyte levels was not reflected by an apparent increase in Y chromosome-positive tubular cells in 15-day postischemic compared with sham-operated or contralateral kidneys.

To determine in these chimeras whether any peritubular cells of bone marrow origin might be peritubular endothelial cells, we counterstained hybridized sections with the endothelial marker vWF. As was found in the GFP chimeras, small numbers of endothelial cells had the Y chromosome (Figure 5E). These results were confirmed by deconvolution microscopy (Figure 5F).

Bacterial $\beta$-gal is not detected in tubular cells of $\beta$-gal chimeras following $I / R$ injury. Prior studies assessing the contribution of bone marrow derived cells to I/R injury and repair have reported high levels of engraftment into tubule cells when $\beta$-gal-expressing bone marrow cells were used $(15,16)$. Using a similar approach, we tested the $\mathrm{I} / \mathrm{R}$ model at 6 weeks after bone marrow transplantation. We confirmed chimerism of irradiated mice transfused with bone marrow from mice expressing the LacZ gene by staining buffy coat leukocytes with X-gal. Nearly all $(91 \% \pm 7 \%)$ leukocytes stained blue compared with $0 \% \pm 0 \%$ of wild-type C57BL/6J blood leukocytes. In addition, when kidneys were harvested for analysis, bone marrow was also stained with X-gal and was found to be nearly completely reconstituted with X-gal-stained cells (Figure 6, A and B). Tissue sections of hematopoietic organs, spleen, and thymus $(n=5$ per time point) from the chimeric mice also exhibited widespread positive staining with $\mathrm{X}$-gal, which confirmed chimerism in the organs of the mice, as did peritoneal macrophages and lung alveolar macrophages (Figure 6C). For example, upon analysis of HPFs, $94 \% \pm 8 \%$ of peritoneal cells (Figure $6 \mathrm{C}$ ) and $79 \% \pm 15 \%$ of spleen cells from chimeric mice $(n=10)$ stained blue with X-gal, whereas $0 \% \pm 0 \%$ of peritoneal cells and $0 \% \pm 0 \%$ of spleen cells from wildtype C57BL/6J animals stained blue with X-gal (data not shown).

$X$-gal staining was elevated in ipsilateral and contralateral kidneys of mice at 2, $7(n=9)$, and 21 days $(n=5)$ following unilateral $\mathrm{I} / \mathrm{R}$ injury induced 6 weeks after bone marrow transplantation. Viewing HPFs (magnification, $\times 400$ ), we detected X-gal staining in a small number of tubular cells. These X-gal-positive tubules colabeled with the proximal tubular cell marker gp330 (Figure 7A). This degree of staining, however, did not differ markedly from that seen in the contralateral kidneys and represented far fewer cells (Figure 7B) than would be expected based on the percentage of PCNA-positive cells (Figure 1C).

Given that the kidney expresses endogenous $\beta$-gal $(20,21)$, the staining in chimeric mice was compared to X-gal staining in kidney 

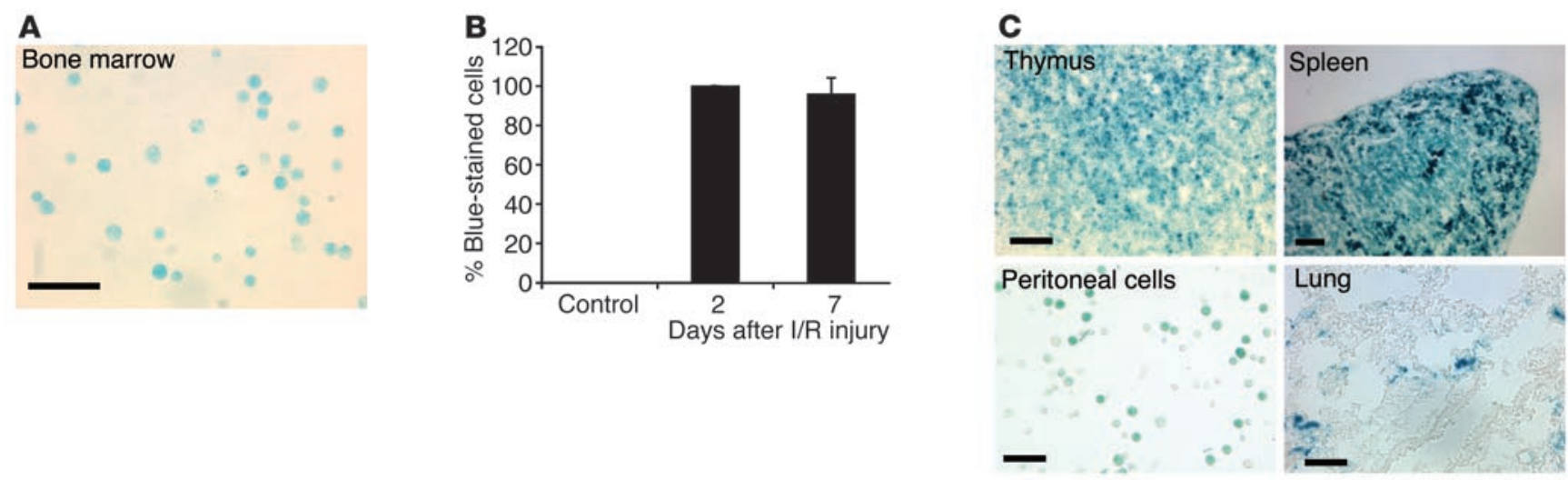

\section{Figure 6}

Confirmation of chimerism in mice transplanted with $\beta$-gal-expressing bone marrow. (A) Fixed bone marrow cells stained blue with X-gal. (B) Percentage of bone marrow cells that stained blue with X-gal in control C57BL/6J mice and chimeric mice $(n=5$ per time point) subjected to I/R followed by 2 days and 7 days of recovery. (C) Peritoneal cells as well as cells of thymus, spleen, and lung from chimeric mice all stained positively with X-gal. Scale bars: $50 \mu \mathrm{m}$.

sections from nonchimeric wild-type C57BL/6J mice after unilateral I/R injury. Sections taken from these nonchimeric mice also had small numbers of tubular cells that stained blue with X-gal solution prepared as described in Methods (Figure 7B). These data suggested that $\mathrm{X}$-gal staining in chimeras might be detecting endogenous $\beta$-gal activity. Frozen sections from 48 -hour and 7 -day postischemic tissue were immunolabeled with antibacterial $\beta$-gal antibody. By this method, spleen cells labeled strongly for $\beta$-gal in chimeric mice (Figure $7 \mathrm{C}$ ), but the antibody did not detect $\beta$-gal in the postischemic tubular cells (Figure $7 \mathrm{C}$ ). To clarify further whether the $\beta$-gal activity detected by X-gal staining was endogenous or bacterial, we used a commercially produced $\beta$-gal staining set (Roche Diagnostics Corp.) designed to minimize staining from mammalian $\beta$-gal. With these reagents, bone marrow, spleen (Figure 7D), and thymic tissue in chimeric mice stained to a level equal to that seen when the X-gal solution prepared in our laboratory was used as a positive control. By contrast, however, when this commercial X-gal solution was used, tubular cells did not stain for $\beta$-gal either following I/R injury or in contralateral kidneys in chimeric mice (Figure 7D). Careful review of all the ipsilateral and contralateral kidney sections from chimeric mice, taken 2,7 , and 21 days after ischemia, that were stained by this method revealed only 1 positive tubular cell in a contralateral kidney. Tubular cells did not stain positively for $\beta$-gal in control C57BL/6J mice (data not shown).

What might account for occasional positive staining with one $\mathrm{X}$-gal solution and not another? A reduction in $\mathrm{pH}$ of the X-gal staining solution has been reported to result in staining of the mammalian form of $\beta$-gal (21). Using the commercial X-gal solution, which has a $\mathrm{pH}$ of 7.5 , we evaluated whether tubules of postischemic nonchimeric mice were more likely to stain positively if we lowered the $\mathrm{pH}$. When $\mathrm{pH}$ was lowered to 6.5 , we could detect positively stained tubular cells in wild-type C57BL/6J kidney sections (but not spleen sections; Figure 7D). Therefore, when X-gal staining solution has a $\mathrm{pH}$ less than 7.5 , there is significant staining of endogenous $\beta$-gal activity in kidney sections. Careful adjustment of $\mathrm{pH}$ can minimize this unwanted staining. These findings are exemplified by the staining of $0.2-\mathrm{mm}$ tissue sections of normal wild-type C57BL/6J kidneys that had been perfusion-fixed with PLP (2\% paraformaldehyde [PFA], $75 \mathrm{mM}$ L-lysine, and $10 \mathrm{mM}$ sodium periodate) (Figure 7E). The commercial staining set ( $\mathrm{pH}$ 7.5; Roche Diagnostics Corp.) detected a minimal level of endogenous $\beta$-gal. Much stronger detection was seen when the $\mathrm{pH}$ was reduced to 6.5 . These images indicate that endogenous $\beta$-gal was detected in the kidney tubule at $\mathrm{pH}$ 6.5. When detection in thick tissue sections $(0.2 \mathrm{~mm})$ was minimized (at pH 7.5), tubule staining was attenuated but could still be seen faintly in the outer medulla, precisely the segment of nephron most susceptible to injury from ischemia (Figure 7E). Thick tissue sections $(0.2 \mathrm{~mm})$ of wild-type C57BL/6J kidneys 2 days after ischemia, stained at $\mathrm{pH} 7.5$, also showed a weak diffuse cortical staining pattern, and at $\mathrm{pH} 6.5$, there was much stronger staining in cortical tubules (data not shown). Note that kidney sections from donor LacZ mice had strong kidney tubule staining with X-gal at pH 7.5 (Figure 7F).

After I/R injury, the LacZ chimeric mouse kidneys did not show evidence for endothelial cell replacement, although there were positively stained leukocytes in the interstitium. We reviewed tissue sections from the LacZ donor mice and found that endothelial cells did not stain with the X-gal solution, which suggests that bacterial $\beta$-gal was only weakly expressed in the endothelium. Bone marrow-derived endothelial cells would therefore not be expected to be identified in this chimeric mouse.

Intravenous therapy for $I / R$ injury with bone marrow MSCs ameliorates injury without differentiation into renal structures. Although our data indicated that bone marrow stem cells make only a minor direct contribution to replenishment of postischemic renal structures, we wondered whether direct infusion of bone marrow-derived MSCs might promote stem cell differentiation into renal structures, in particular endothelial cells. Bone marrow MSCs have multipotentiality, as evidenced by their ability to differentiate into a variety of mesenchymal cell types (22). We purified MSCs from EGFP mice (23). These cells did not express lineage markers, or c-kit, but expressed CD34 and Sca-1 when assessed by flow cytometry (Figure 8A). Importantly, in addition to c-kit (which is expressed by endothelial cells), they did not express other endothelial cell markers, including CD31. The MSCs were highly fluorescent with EGFP and could be induced 
A

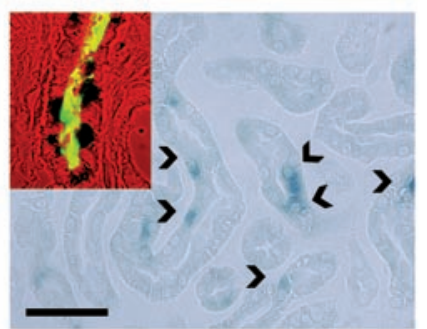

B

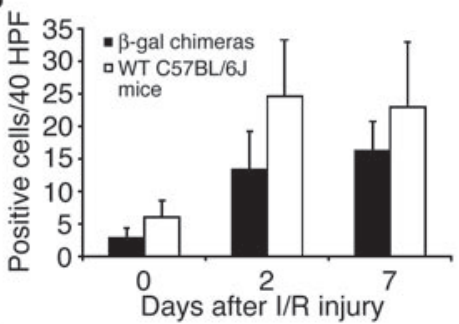

C

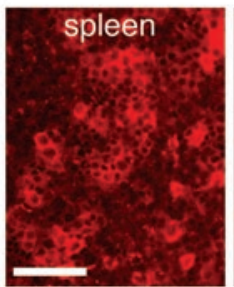

D

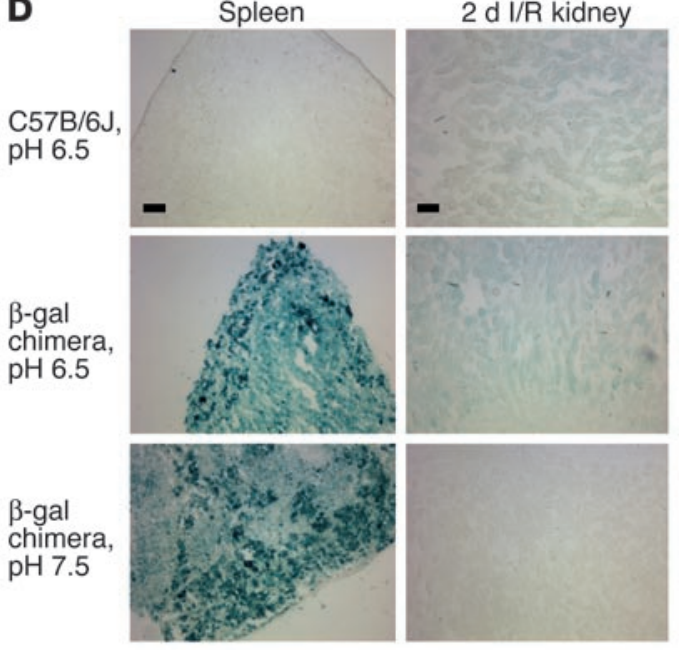

E

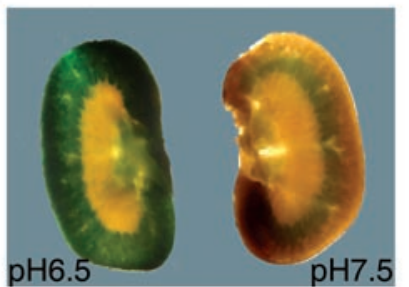

F

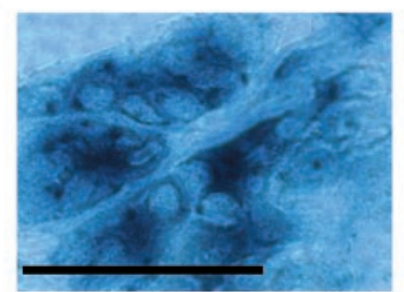

Figure 7

$X$-gal stains tubular cells in the kidney of wild-type mice, reflecting endogenous $\beta$-gal activity, but can be distinguished from bacterial $\beta$-gal when high-pH X-gal staining or anti- $\beta$-gal antibodies are used. (A) Occasional tubular cells stained blue, indicating $\beta$-gal, 7 days following l/R injury in chimeric mice (arrowheads). X-gal-stained cells colabeled with the proximal tubular cell marker gp330, seen as green fluorescence (inset). (B) The number of X-gal-positive cortical and outer medullary tubular cells per $40 \mathrm{HPF}$ in contralateral kidneys ( 0 days) and in kidneys of both chimeric and wild-type C57BL/6J mice following I/R injury. Note that I/R resulted in an increase in the number of $\beta$-gal-stained cells in both nonchimeric and chimeric mice. (C) Sections at day 7 after l/R labeled with anti- $\beta$-gal antibodies. Note the bright staining in spleen cells (left) but no staining in regenerated tubules (right) (D) Sections (magnification, $\times 100$ ) of I/R kidneys and spleen from wild-type $(n=3$ per time point) and chimeric mice $(n=5$ per time point) stained with X-gal solution at pH 6.5 or 7.5. Note faint blue tubules in kidneys of wild-type and chimeric animals (compare top and middle panels). Blue staining in kidney tubules but not spleen is suppressed using X-gal in solution at pH 7.5 in chimeric mice (compare bottom and middle panels). (E) Sagittal sections $(0.2 \mathrm{~mm}$ ) of normal C57BL/6J kidney stained with X-gal solution at pH 6.5 (left) and pH 7.5 (right). Note widespread cortical and outer medullary staining at low pH and milder restricted staining in the outer medulla at higher pH. (F) Kidney section (magnification, $\times 400$ ) from LacZ donor mouse stained with X-gal, $\mathrm{pH}$ 7.5. Note intense blue staining of tubules indicative of bacterial $\beta$-gal. Scale bars: $50 \mu \mathrm{m}$.

in vitro to differentiate into endothelial-like structures and adipocytes (Figure 8, B and C), which confirmed the multilineage potential of the MSCs. In the case of endothelial-like structures, these labeled strongly with anti-CD31 antibody (Figure 8B). As quantitated by flow cytometry, $1.8 \% \pm 0.5 \%$ of MSCs exhibited a 100- to 1,000-fold increase in expression of CD31 when cultured on Matrigel (data not shown), which provides further evidence that MSCs have the capacity to develop an endothelial phenotype. MSCs were cultured on tissue culture grade plastic. Mice were subjected to bilateral I/R injury, followed by i.v. injections of MSCs $\left(0.5 \times 10^{6}\right.$ cells per injection $)$ immediately after surgery and at 24 hours after ischemia. In our initial studies, peak plasma creatinine levels at 24 hours were no different in mice receiving MSCs or an injection of control medium (PBS) (Figure 8E). Organs examined by fluorescent microscopy at 24 and 48 hours provided no evidence for implantation of MSCs. The experiments were repeated using MSCs that had been cultured on Matrigel. A control cell type, embryonic fibroblasts, was prepared identically. Injection of MSCs reduced the severity of
$\mathrm{ARF}$ as measured by the creatinine level at 24 hours (Figure 8E). This effect was, however, also seen when embryonic fibroblasts, grown on Matrigel, were injected (Figure 8F). We examined these kidneys by fluorescence microscopy 24 hours, 48 hours, 7 days, and 15 days after I/R injury. There was no evidence of MSCs in the kidney parenchyma. We did not find 1 example of EGFPexpressing cells in any of these kidneys. Furthermore, we examined other organs, in particular lung and spleen, where there was also no evidence for MSCs implantation. Analysis of bone marrow at 15 days by flow cytometry revealed a small population of EGFP-fluorescent cells (less than 1\%), which suggests that MSCs had homed to the marrow cavities.

We further explored the potential of MSCs to become renal structures by direct intrarenal parenchymal injection of MSCs following ischemic injury. Two hours following injection of MSCs $\left(0.5 \times 10^{6}\right)$ into the cortex of the normal or postischemic kidney, viable MSCs could be identified by microscopy (Figure 8D). However, 24 hours later, there was no evidence of EGFP cells in the kidney. These results are comparable to those of an earlier study, in 
A

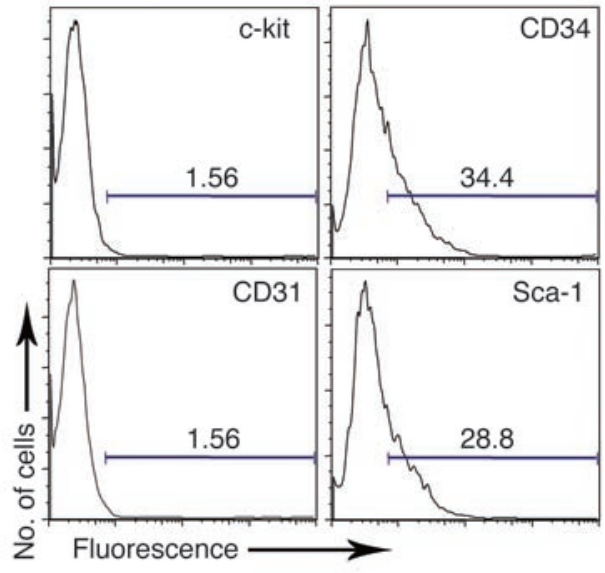

B

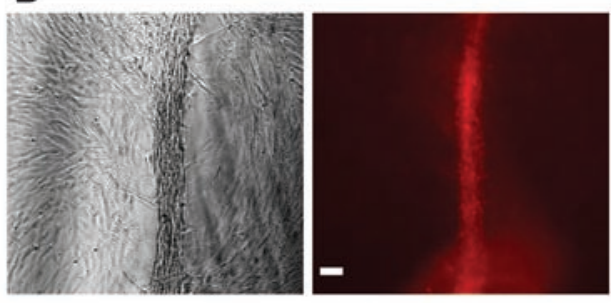

C
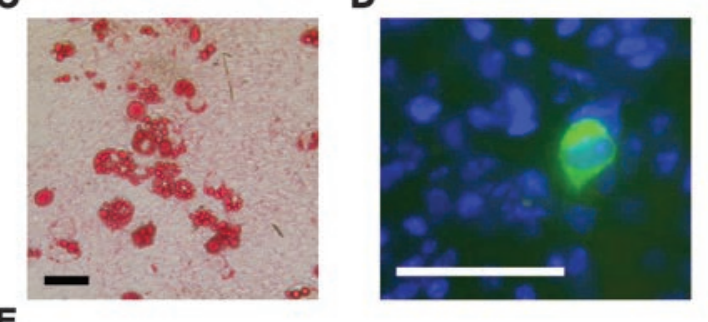

$\mathbf{E}$

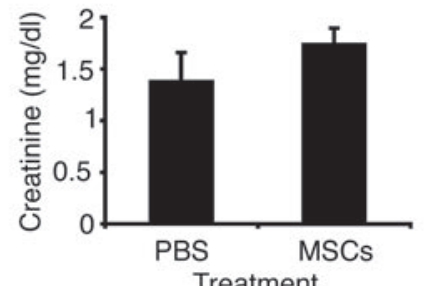

$\mathbf{F}$

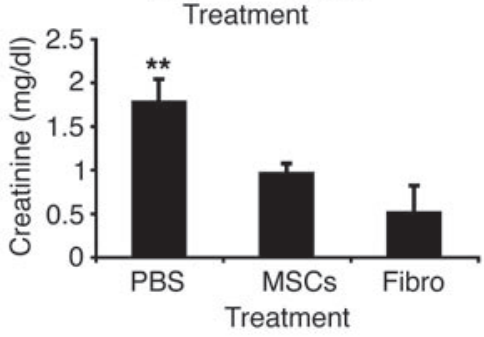

\section{Figure 8}

Bone marrow MSCs have multilineage potential and are protective in ischemic injury without differentiating into tubule cells. (A) Flow cytometry of MSCs for cell surface stem cell markers. Compared with isotype control labeling, which was used to define the marker (data not shown), MSCs lacked expression of c-kit and CD31 but expressed CD34 and Sca-1 (values are expressed as percent positive compared with isotype control antibody labeling). (B) Photomicrograph of MSCs differentiated into capillary-like structures (left). The same structure shows strong immunofluorescent labeling with the endothelial marker CD31 (right). (C) Photomicrograph of MSCs differentiated in vitro into adipocytes and labeled with oil red O for lipid. (D) Fluorescence micrograph showing an EGFP-expressing MSC in the cortex of the postischemic kidney 2 hours after intraparenchymal injection of EGFP-labeled MSCs. (E) Plasma creatinine levels 24 hours after 30-minute bilateral I/R renal injury followed by i.v. injection of control PBS or $0.5 \times 10^{6}$ MSCs cultured on plastic ( $n=4$ per group). (F) Plasma creatinine levels 24 hours after 30-minute bilateral I/R renal injury followed by i.v. injection of control PBS, $0.5 \times 10^{6} \mathrm{MSC}$ cultured on Matrigel, or embryonic fibroblasts (Fibro) cultured on the same matrix. Note that the level of creatinine was significantly higher in PBS-treated mice $\left(n=7\right.$ per group; ${ }^{* *} P<0.01$, ANOVA). Scale bars: $50 \mu \mathrm{m}$.

which the fate of MSCs was traced in irradiated mice (22). In this study, MSCs homed to the bone marrow only. Our data indicate that, while an injection of cells i.v. can have a therapeutic effect on the course of functional impairment due to I/R when cells are grown under specific conditions, this effect is independent of implantation and differentiation into renal structures.

Hematopoietic lineage-negative lenkocytes. Although we found no evidence for differentiation of bone marrow-derived cells into tubular cells, we did find evidence for differentiation into endothelial cells in the injured kidney. It was important therefore to determine whether renal injury mobilized stem cells from the bone marrow to the blood, as has been suggested in other reports $(15,24)$. Bone marrow-derived HSCs and MSCs lack lineage markers, but the identity of cell surface markers of endothelial precursors remains ambiguous. In some studies, endothelial precursors have also been shown to lack lineage markers $(24,25)$. Blood leukocytes purified from healthy mice or mice 24 and 48 hours following ischemic injury were labeled with antibodies to lineage markers and analyzed by flow cytometry (Figure 9). In healthy mice, a small population of leukocytes (less than $1 \%$ ) was hematopoietic lineage-negative $\left(\operatorname{lin}^{-}\right)$. We found no evidence for an increase in this negative population at 24 hours (data not shown) or at 48 hours (Figure 9) following injury.

\section{Discussion}

Our studies focused on the importance of BMSCs in a model of severe ischemic injury of the kidney, which is characterized by organ failure with subsequent recovery. In this model, many tubular cells of the outer medulla die by necrosis and apoptosis (26), and in surviving cells, there is widespread cytoskeletal disruption. Injury is followed by cytoskeletal reorganization and intense tubular cell proliferation during the recovery phase. We used 3 different reporters to identify bone marrow-derived cells to evaluate whether these cells contribute directly to the repair of the epithelium after injury. The use of 1 reporter, EGFP, provided no evidence for direct BMSC involvement in tubular cell regeneration. Bone marrow cells did, however, make a small contribution to repopulation of the injured vascular endothelium and could indirectly affect tubule regeneration. These results were supported by examination of sex-mismatched chimeras. There was a low level of false positive results when in situ hybridization was used to detect the Y chromosome. This false positivity was eliminated when deconvolution microscopy was used to define better the $3 \mathrm{D}$ tissue relationship of tubule cells to leukocytes and other interstitial cells (27). The use of another reporter, $\beta$-gal, suggested a small contribution from bone marrow-derived cells to tubular cell replacement. Closer examina- 


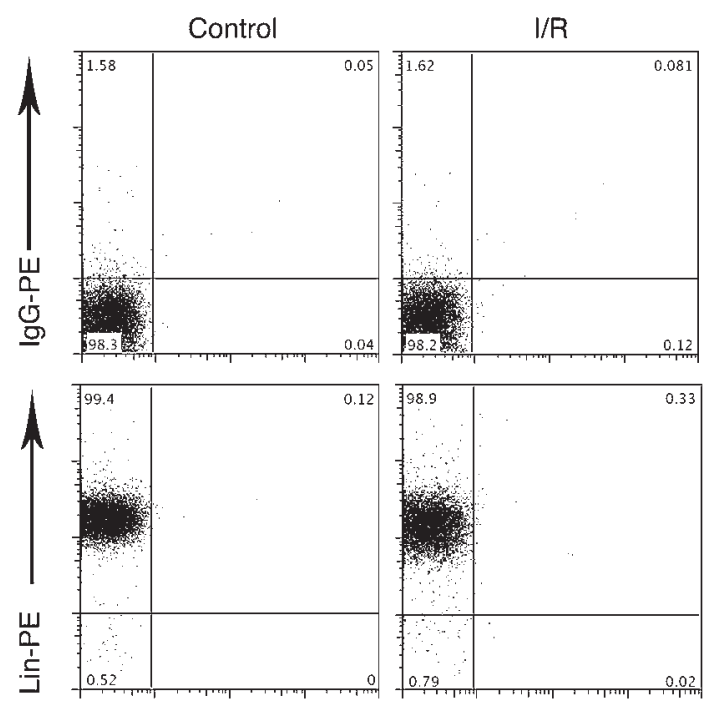

Figure 9

The proportion of lin- blood leukocytes does not increase following I/R injury. Flow cytometry plots (representative of $n=6$ ) of blood leukocytes from healthy mice (left) or mice 2 days following bilateral renal ischemia (right), labeled with PE-fluorescent antibodies against lineage markers (Lin-PE) (CD11b, Gr-1, CD4, CD8, B220, Ter-119) or IgG control antibodies. Note that a minority $(<1 \%)$ of leukocytes were lin $^{-}$in control mice, and this percentage was not increased in mice 2 days following I/R injury.

tion of this reporter model indicated that endogenous $\beta$-gal in the tubular cells of the inflamed postischemic kidney could account for all of the $\beta$-gal-positive tubular cells.

Our I/R model resulted in disruption of the actin cytoskeleton in most of the intact tubular cells in the outer stripe of the outer medulla 48 hours after ischemia as reflected by phalloidin staining (18). Three weeks after ischemia, the disrupted tubules had almost completely returned to normal. We and others have demonstrated that spreading, dedifferentiation, and then proliferation of viable cells occur during recovery from renal I/R injury (3). In our previous study (3) and our current study, tubular cell proliferation was demonstrated to be prominent. In the absence of BMSCs differentiating into tubular cells, it is probable that regenerating tubular cells derive from dedifferentiated cells of tubular origin that have survived the initial ischemic insult, divide, and are able to redifferentiate into the mature tubular cell phenotype.

Recent reports suggest that there is significant plasticity in the developmental potential of many different adult cell types, although adult stem cells appear to be more limited than their embryonic counterparts in proliferative capacity and pluripotentiality $(8,28)$. Recently, some studies have provided evidence that adult bone marrow cells can give rise to or fuse with cells outside their tissue of origin, including heart, brain, and liver (29-31). Several reports also indicate that cells of bone marrow origin can become functioning endothelial cells and that this population is important in revascularization following injury (32-37). Our findings are consistent with such observations on the endothelium and focus attention on the renal vasculature as an important site for repair. Although frequently overlooked, evidence for the importance of vascular repair in the injured kidney was provided in recent studies in which direct administration of endothelial cells into postischemic kidney circulation was reported to hasten recovery $(37,38)$ and longer-term studies showing that the postischemic kidney is characterized by loss of capillaries in the outer medulla that are not fully regenerated (39). Bone marrow-derived endothelial cells may possess a greater capacity to proliferate and as such are likely important contributors to vascular recovery from injury (40). The fact that many fewer endothelial cells in contralateral kidneys are replaced by cells originating from the bone marrow suggests that bone marrow cell differentiation in the mouse kidney contributes more to replenishing the endothelial cells lost due to injury than to the replenishing of endothelial cells during normal cell turnover. Compared with the contribution of bone marrow-derived endothelial cells to vascularization of other organs including hind limb and tumorigenesis $(34,41)$, the contribution of bone marrow cells to revascularization in our model of kidney repair appears only to be minor, and it is unlikely, therefore, that bone marrow cells contribute significantly to regeneration. Whether this finding reflects impaired revascularization in the regenerating kidney, as has been suggested in other studies (39), remains to be explored.

Previous investigation of the role of BMSCs in the injured kidney has focused on tubular cell regeneration. Bone marrow cells have been reported to contribute to both normal turnover of renal epithelium in mice (5\% of tubular cells after 13 weeks of chimerism) and regeneration in human renal transplantation (up to $6.8 \%$ after 3 months) (14). These provocative observations have been pursued by others who suggest in 1 study that, 7 days following ischemic injury, $20 \%$ of all tubules in the outer medulla are replaced by bone marrow-derived cells $(15,16)$. In another study of mild ischemic injury, which was not completely characterized, $80 \%$ of all tubules were reported to contain differentiated tubular cells of bone marrow origin only 24 hours following ischemia (16). Both these studies, which were performed in the same mouse strain we used, relied heavily on staining for $\beta$-gal activity with X-gal. Furthermore, in 1 report, replacement with bone marrow cells appeared to occur at a time when cell death and cell sloughing predominate (16). It is our contention that the tubular cell $\beta$-gal staining reported previously may reflect endogenous $\beta$-gal. Our study indicates that native mouse kidney tubules have high levels of endogenous $\beta$-gal, which, following mild fixation, stains strongly with X-gal if the $\mathrm{pH}$ is lower than 7.5. Even at high $\mathrm{pH}$, after mild fixation of thick $(0.2 \mathrm{~mm})$ sections, endogenous $\beta$-gal activity can be detected weakly in the outer medulla of normal kidneys and diffusely in the cortex in postischemic kidneys. It is possible, therefore, that endogenous $\beta$-gal is more easily stained in the postischemic kidney, and this staining can easily be interpreted as bacterial $\beta$-gal activity derived from donor cells in this model. When we minimized detection of endogenous but not bacterial $\beta$-gal activity, tubular epithelial cells in 5 - $\mu \mathrm{m}$ sections did not exhibit $\beta$-gal activity. Furthermore, bacterial $\beta$-gal-specific antibody did not locate antigen in tubular cells. In our opinion, the $L a c Z$ chimeric mouse expressing bacterial $\beta$-gal in bone marrow cells is an unreliable model for tracking bone marrow-derived cells in the adult kidney. When we used sex-mismatched chimeras to identify cells of bone marrow origin, we found very small numbers of tubular cell nuclei that stained for the Y chromosome. The same few apparently positive cells were analyzed by deconvolution microscopy. When this technique was used, it became apparent that aggregates of fluorescent probe were 
located outside of the nucleus, which indicates that these cells did not have true nuclear Y chromosome positivity. Recently, in a detailed study of epithelial cells in enteric human biopsies from human sex-mismatched bone marrow transplants, it was pointed out that conventional microscopy markedly overestimated the number of bone marrow-derived epithelial cells (27). Therefore, detailed $3 \mathrm{D}$ microscopy of tissue is required for definitive scoring of Y chromosome-positive nuclei. Because tissues from EGFP chimeric mice require no fixation and mice do not endogenously express GFP, we have found the EGFP chimeric model to give superior results, with greater sensitivity and specificity over other approaches. In addition, colocalization studies can be performed using 1-step antibody procedures on these tissues, which further enhances the specificity of findings.

The precise phenotype of BMSC precursors that differentiate into endothelial cells is currently unclear. Contrasting reports show that bone marrow stromal cells, c-kit ${ }^{+} \mathrm{BMSCs}$, inn $^{-} \mathrm{c}-\mathrm{Kit}^{+} \mathrm{Sca}{ }^{+}$ BMSCs, or monocytes have the potential to become endothelial cells (42-45). Nevertheless, bone marrow stromal cells have been reported to differentiate into endothelial cells in vitro and assist in tumor vascularization in vivo (44). We therefore injected bone marrow stromal cells i.v. and found that they did not home to the injured kidney, even following differentiation into capillary structures in vitro. Interestingly, they could not be found in other organs (lung, heart, spleen, liver) 2 weeks after injection, but small numbers homed to the bone marrow, which was in keeping with previous observations (46). Although MSCs did not differentiate into renal structures in vivo, they had the capacity to reduce the severity of ARF following I/R injury. This protective capacity was not restricted to MSCs, since fibroblasts grown under identical conditions had the same efficacy. By contrast, MSCs grown on plastic had no such protective effect. Further work will be required to determine the cause of this protective effect. Some possibilities include cytokine release by injected cells, inadvertent injection of cell substrate, the release of antiinflammatory cytokines such as IL-10 following apoptotic cell death of injected cells, or the immunomodulatory effects of clearance of circulating cells by splenic phagocytes $(47,48)$.

Although we were unable to positively identify MSCs as the stem cells responsible for replacement of endothelial cells in the postischemic kidney, it remains possible that HSCs were mobilized from the bone marrow, as reported by others, or that they derive from a subset of circulating monocytes $(15,16)$. We searched carefully for an increased population of circulating leukocytes lacking lineage markers CD11b, GR-1, CD4, CD8, B220, Ter-119 at 24 and 48 hours following induction of injury in our model. We have failed repeatedly to see a mobilized, distinctly lin ${ }^{-}$population of circulating leukocytes. Although there is no mobilized population of lin $^{-}$cells in the circulation, up to $1 \%$ of peripheral leukocytes are lin $^{-}$in both healthy and diseased mice and therefore represent a large enough pool to account for the cell replacement we have observed.

Recently, controversy over the importance of BMSCs in solid organ repair has been generated by findings that cardiomyocyte replacement following infarction and pancreas $\beta$ cell regeneration can both proceed without the involvement of stem cells (49-51). Our findings in the kidney reinforce our hypothesis that the tubule has an enormous capacity to repair itself as a result of dedifferentiation of proximal tubule epithelial cells followed by proliferation and reestablishment of a differentiated phenotype (52). Our findings that bone marrow-derived cells can differentiate into kidney endothelial cells or fuse with these cells suggests that the recovering kidney may benefit from circulating endothelial cell precursors. In the injured pancreas, liver, and heart, studies point to progressive replacement with BMSC-derived endothelial cells over a number of weeks $(32,53)$. It is possible therefore that further repair of peritubular capillaries by BMSCs in the postischemic kidney occurs in ensuing weeks.

Our studies do not definitively exclude a role for kidneyderived mesenchymal stem cells in repopulation of the ischemically injured renal tubule. The identification of a population of cells within the kidney that has the capacity to differentiate into tubular cells has remained elusive (54), although there is a recent report of multipotent stem cells in the renal papilla (55). In our studies, very early after injury, a large number of proliferating cells could be seen at diverse sites in the regenerating tubules. In order for large numbers of proliferating cells to be derived from endogenous kidney stem cells, a large population of stem cells would have to be present and adjacent to or within proximal tubules, and the intrinsic low proliferation rate of such stem cells would have to be enhanced dramatically. Our findings that bone marrow-derived cells differentiate into or fuse with peritubular vascular endothelial cells suggests possible therapeutic strategies focused on enhancing this process.

We conclude that bone marrow-derived cells do not make a significant contribution to the restoration of epithelial integrity after an ischemic insult and that epithelial cells that restore tubular integrity in the postischemic kidney primarily originate in resident surviving epithelial cells that undergo a phenotypic transition resulting in dedifferentiation, proliferation, and subsequent differentiation of the parent and daughter cells into mature polar epithelial cells. It is hoped that understanding the factors regulating this behavior of the kidney epithelial cell will lead to insight into therapeutic approaches to activate and potentiate this response in patients where it seems to be impaired.

\section{Methods}

Chimeric mice. Bacterial $\beta$-gal-transgenic mice expressing the LacZ gene (B6.129S7-Gtrosa26), EGFP [C57BL/6-TgN(ACTbEGFP)10sb] mice, and wild-type C57BL/6J mice were obtained from the Jackson Laboratory. Wild-type isogenic recipient mice (aged 8-12 weeks) were lethally irradiated using ${ }^{137} \mathrm{Cs}$ irradiator (single dose of 1,000 rads over 30 minutes). Whole bone marrow was collected from limb bones of male C57BL/6J, $\beta$-gal-, and EGFP-transgenic mice. Ten million cells in $200 \mu \mathrm{l}$ of PBS were injected into the lateral tail vein of recipients 2 hours later, in accordance with a protocol approved by the Harvard Center for Animal Resources and Comparative Medicine. Recipients were housed in sterile conditions, and chimerism was confirmed at 5 weeks by either flow cytometry (GFP chimeras) or X-gal staining (LacZ chimeras) of buffy coat cells.

$I / R$ injury models. Six weeks following bone marrow injections (see above), mice ( $\beta$-gal, $n=9$ per group; EGFP, $n=4$ per group; sex mismatched, $n=4$ per group) were anesthetized with pentobarbital $(65 \mu \mathrm{g} / \mathrm{g}$ body weight) and subjected to 30 minutes (male) or 45 minutes (female) of left unilateral kidney ischemia. Male mice are more susceptible to injury than females, and these time differences give equivalent functional injury (56). The contralateral kidney was exposed to sham surgery. Kidneys were exposed through flank incisions. Ischemia was induced by clamping of renal pedicles with nontraumatic microaneurysm clamps (Roboz Surgical Instruments Co.). The incisions were temporarily closed during ischemia or sham surgery and body temperature maintained at 
$36.5-37.3^{\circ} \mathrm{C}$. After the clamps were removed, reperfusion of the kidneys was confirmed visually. Mice were hydrated with 1-ml aliquots of saline administered i.p. Kidneys were harvested 2, 7, 15, or 21 days after the surgery. In all cases, tissues were flushed, via intracardiac catheter, with ice-cold PBS or fixative to remove blood-borne leukocytes and erythrocytes. In addition, bone marrow, blood leukocytes, peritoneal leukocytes, spleen, thymus, and lung were also harvested for analysis. In wild-type nonchimeric (C57BL/6J) mice ( $n=4$ per group), unilateral ischemia was also performed in a manner identical to that described above. In sexmismatched chimeric ( $n=4$ per group) and wild-type C57BL/6J male mice ( $n=4$ per group), bilateral ischemic injury was induced as previously described (57). In brief, animals were anesthetized and prepared as described above. Immediately following clamping of the left renal pedicle, the right pedicle was also clamped. Both kidneys were clamped for 30 minutes precisely and both treated identically. Tail bleeds were taken 7 days prior to surgery and 2 and 7 days after ischemia and plasma assessed for creatinine levels (Creatinine Analyzer II; Beckman Coulter).

Culture and differentiation of bone marrow MSCs. MSCs were purified from whole bone marrow of EGFP mice as previously described (23). Cultured MSCs were used between passage 1 and 6 for all experiments. Cells were cultured in Iscove's modified DMEM supplemented with FCS and horse serum and maintained at low cell density (23). Cells were differentiated into adipocytes as previously described (23). To promote differentiation into endothelial cells, we prepared Matrigel-coated (BD) plates. Into wells of $3.5-\mathrm{cm}$ diameter, $0.5 \times 10^{6} \mathrm{MSCs}$ were plated in endothelial growth medium (EGM-2; Cambrex). Medium was changed every 48 hours. After 2 days, cells formed interconnecting tubes with branches, reminiscent of capillaries. EGFP-fluorescent MSCs cultured on Matrigel for 5 days were separated from the gel using cell recovery solution (BD Biosciences), followed by trypsin $(0.25 \%)$ and EDTA $(0.1 \%)$ to yield a single-cell preparation. Two hours following I/R injury, mice received $0.5 \times 10^{6} \mathrm{MSCs}$ by lateral tail vein injection in $200 \mu \mathrm{l}$ PBS. In some experiments, the MSCs were cultured on tissue culture plastic, and in others, MSCs had been cultured on Matrigel as described above. Control mice received aliquots of PBS by the same route or an injection of primary embryonic fibroblasts from C57BL/6J mice prepared as previously described (58) and grown under identical conditions on Matrigel. In some experiments, these cells were labeled with a cell tracker, BCECF ( $2 \mu \mathrm{M}$; Invitrogen Corp.), in order that they could be traced in vivo. In some experiments, organs were assessed at 24 hours. In other experiments, a second injection was given at 24 or 48 hours and organs assessed at 48 hours or 7 days, respectively ( $n=4$ per group). In additional experiments, mice received injections of MSCs $(n=6$ per group) at 2 hours, 24 hours, 5 days, and 7 days following I/R injury. Organs were then assessed at 15 days. In still other experiments, 2 hours following I/R injury, kidneys received a total of $0.5 \times 10^{6} \mathrm{MSCs}$ injected intracortically in 3 separate locations in the sagittal mid-line. Organs were assessed at 2 hours, 2 days, or 7 days following injection ( $n=4$ per time point).

Immunocytochemistry and $\beta$-gal staining. Tissues were snap frozen in OCT or fixed with PLP fixative. After 2 hours, fixed tissues were transferred to PBS containing $18 \%$ sucrose overnight $\left(4^{\circ} \mathrm{C}\right)$, then stored at $-80^{\circ} \mathrm{C}$. For sex-mismatched mice, tissues were fixed in $10 \%$ formalin or methyl Carnoy fixative for 12 hours, then were dehydrated through $70-100 \%$ ethanol, transferred to xylene, and paraffin blocked. Three-micrometer sections were cut. For $\beta$-gal chimeras, $5-\mu \mathrm{m}$ cryotome cut sections were dried, washed in PBS for 10 minutes, incubated in blocking buffer ( $1 \mathrm{mM} \mathrm{MgCl}_{2}, 0.01 \% \mathrm{Na}$-deoxycholate, $0.02 \%$ IGEPAL-CA630, and $5 \mathrm{mM}$ EGTA in PBS) for 20 minutes at room temperature, and incubated in the X-gal mixture [1 $\mathrm{mM} \mathrm{MgCl}_{2}, 0.01 \%$ Na-deoxycholate, 0.02\% IGEPAL-CA630, $5 \mathrm{mM}$ EGTA, $5 \mathrm{mM} \mathrm{K}_{3} \mathrm{Fe}(\mathrm{CN})_{6}, 5 \mathrm{mM} \mathrm{K}_{4} \mathrm{Fe}(\mathrm{CN})_{6} .3 \mathrm{H}_{2} \mathrm{O}$, and $1 \mu \mathrm{g} \mathrm{X}$-gal; all from Sigma-Aldrich] for 16 hours at $37^{\circ} \mathrm{C}$. Alternatively, dried, washed sections were incubated for 16 hours with a commercially available $\beta$-gal staining set, specifically designed to minimize staining from endogenous $\beta$-gal (Roche Diagnostics Corp.). Following staining, sections were washed, then mounted with VECTASHIELD (Vector Laboratories). To immunolabel bacterial $\beta$-gal, air-dried 5 - $\mu \mathrm{m}$ sections from snap frozen tissues were treated with avidin, then biotin (Vector Laboratories) to block endogenous biotin, then pre-blocked with Fc Block (BD Biosciences - Pharmingen) in 10\% rabbit serum. Sections were incubated with biotinylated anti- $\beta$-gal antibody (1:200; Sigma-Aldrich) followed by streptavidin, Alexa Fluor 594 conjugate (1:2,000; Invitrogen Corp.), then mounted as above.

For EGFP chimeras, tissues were prepared as described above. PLPfixed and snap-frozen unfixed, cryotome-cut 5 - $\mu \mathrm{m}$ sections were mounted in VECTASHIELD (Vector Laboratories) and viewed directly. For examination of tissues following injection of EGFP fluorescent MSCs, snap-frozen unfixed 5 - $\mu \mathrm{m}$ sections were mounted and viewed directly. In addition, sections were blocked with donkey serum and labeled with rabbit anti-GFP antibodies (1:200; Invitrogen Corp.) or chicken antiGFP antibodies (1:500; Aves Laboratories), followed by anti-rabbit-Cy3 or anti-chicken-Cy2 (Jackson Laboratory) to exclude the presence of MSCs expressing low levels of EGFP in the kidney.

Proximal tubules in $\beta$-gal chimeric tissue were identified by the expression of gp330 (59). To stain for gp330, sections were preblocked ( $2 \%$ BSA in PBS), then incubated with rabbit polyclonal anti-gp330 antibody $(1: 500)$ in donkey serum for 60 minutes. Washing was followed by incubation with FITC-conjugated anti-rabbit antibody (1:300) for 30 minutes at room temperature (Jackson Laboratory), and sections were mounted in VECTASHIELD (Vector Laboratories). To visualize the actin cytoskeleton, we stained tissues with phalloidin-Cy3 as previously described (57). To quantify the proliferation of cells in the tubules, $40 \mathrm{HPFs}$ in the outer medullary regions of PAS-stained sections were examined for mitotic cells adherent to basement membrane within tubules. Tubular cell proliferation was also assessed by labeling for PCNA as previously described (18). Briefly, sections were boiled in $10 \mathrm{mM}$ citrate buffer ( $\mathrm{pH}$ 6.0) for $10 \mathrm{~min}$ utes, equilibrated in PBS, then labeled with anti-PCNA antibody (1:200; DakoCytomation) in $10 \%$ goat serum followed by goat anti-mouse FITC (1:200; Sigma-Aldrich). Sections were mounted as above, counterstained with DAPI, then visualized by fluorescence microscopy for tubular cell nuclei containing green fluorescence. Forty HPFs of the outer medullary region were scored for PCNA-positive cells in normal kidney and at 2 days and 7 days after ischemia. For confocal microscopy, sections were preblocked with Fc Block (BD Biosciences - Pharmingen), then labeled with anti- $\alpha$-SMA-Cy3 (1:200; Sigma-Aldrich), anti-CD11b-PE (1:200), anti-B220-PE (BD Biosciences - Pharmingen), anti-CD45-PE (eBioscience), or goat anti-vWF (1:200; Santa Cruz Biotechnology Inc.) followed by donkey anti-goat Alexa Fluor 594 (1:1,800; Invitrogen Corp.) or rat anti-mouse CD31 (1:200; eBioscience) followed by preabsorbed goat anti-rat Cy3 (1:400; Jackson Laboratory). Sections were mounted with VECTASHIELD and analyzed with a PerkinElmer spinning disk confocal microscope using laser light at 488 and $568 \mathrm{~nm}$. Sex-mismatched tissues were dewaxed and labeled with either biotinylated lotus lectin (1:500; Vector Laboratories) or rabbit anti-vWF (1:400; Chemicon International), followed by biotinylated goat anti-rabbit antibodies (1:400; Vector Laboratories). Staining was achieved using the VECTASTAIN ABC-AP kit followed by the fluorescent Vector Red stain.

Fluorescent in situ bybridization. Paraffin sections were dewaxed and rehydrated. Immunolabeling was performed (see above). Once stained, sections were incubated with $1 \mathrm{M}$ sodium thiocyanate at $80^{\circ} \mathrm{C}$ for 10 minutes, which was followed by digestion with proteinase $\mathrm{K}$ at $37^{\circ} \mathrm{C}$ for 
15 minutes, then $0.1 \mathrm{M} \mathrm{HCl}$ at $37^{\circ} \mathrm{C}$ for 10 minutes. After postfixation with $4 \%$ PFA, sections were dehydrated and air-dried. STAR-FISH mouse $Y$ chromosome-specific probe (Cambio) was added in the manufacturer's buffer, and sections were sealed with a coverslip and rubber cement. Slides were heated to $80^{\circ} \mathrm{C}$ for 10 minutes and then incubated overnight at $37^{\circ} \mathrm{C}$. After the coverslip was removed, sections were stringently washed at $37^{\circ} \mathrm{C}$ as follows: with $\times 2$ SSC for 5 minutes, formamide/SSC $(50 \% \mathrm{wt} / \mathrm{vol})$ for 5 minutes (repeated), $\times 2$ SSC for 5 minutes (repeated), $\times 4$ SSC/ $0.05 \%$ Tween for 5 minutes, $\times 1$ SSC for 5 minutes, and $\times 0.5$ SSC for 5 minute. Slides were then mounted with VECTASHIELD/DAPI (Vector Laboratories) and sealed before viewing. Deconvolution was performed using software from AutoQuant Imaging Inc.

FACS analysis. Bone marrow was harvested from the femurs of EGFP chimeras or transgenic EGFP mice as previously described (60). Citrated blood ( $0.38 \%$ final concentration) was centrifuged (1,500 $g$ for 10 minutes) and leukocytes separated from erythrocytes by removal of the buffy coat. Residual erythrocytes were removed from leukocytes by red cell lysis using ammonium chloride, potassium (ACK) lysis buffer. Leukocytes and bone marrow were washed in PBS, then fixed with 1\% PFA, prior to analysis for the proportion of cells with green fluorescence. In some experiments, leukocytes were also labeled with antibodies to lineage markers (CD11b, Gr-1, B220, CD4, CD8, Ter-119) (eBioscience) using methods previously described (61). In brief, $2.5 \times 10^{5}$ leukocytes were resuspended in FACS buffer $(100 \mu \mathrm{l})$ containing anti-CD11b-PE antibodies (monocytes and neutrophils), a combination of anti-B220-PE, anti-CD4-PE, anti-CD8-PE antibodies (lymphocytes), or a combination of all lineage markers (as described above). Cultured EGFP-fluorescent MSCs were labeled with anti-CD34-PE antibodies (BD Biosciences - Pharmingen) or anti-CD31, anti-c-Kit, antiSca-1 (eBioscience), followed by anti-rat PE antibodies (Vector Laboratories). In each case, we determined nonspecific binding by labeling cells with an equal concentration of IgG-PE or IgG control antibody (eBioscience). After washing, cells were fixed with $1 \%$ PFA prior to analysis.

Statistics. All data showing value with assessment of error are expressed as mean \pm SEM. Differences among groups were assessed by analysis of variance and between groups by Mann-Whitney rank-sum test.

\section{Acknowledgments}

D. Prockop and A. Peister (Tulane University, New Orleans, Louisiana, USA), are gratefully acknowledged for providing EGFP-fluorescent MSCs. J.S. Duffield is supported by a Senior Fellowship from the National Kidney Research Fund (United Kingdom). K.M. Park is supported by a Korea Research Foundation grant and a Young Investigator grant from the National Kidney Foundation. This work was supported by NIH grants DK 39773 and DK 38452 (to J.V. Bonventre).

Received for publication June 30, 2004, and accepted in revised form May 3, 2005.

Address correspondence to: Joseph V. Bonventre, Harvard Institutes of Medicine, 5th Floor, Brigham \& Women's Hospital, 4 Blackfan Circle, Boston, Massachusetts 02115, USA. Phone: (617) 525-5960; Fax: (617) 525-5965; E-mail: joseph_bonventre@hms.harvard.edu.
1. Thadhani, R., Pascual, M., and Bonventre, J.V. 1996. Acute renal failure. N. Engl. J. Med. 334:1448-1460.

2. Zuk, A., Bonventre, J.V., Brown, D., and Matlin, K.S. 1998. Polarity, integrin, and extracellular matrix dynamics in the postischemic rat kidney. Am.J. Physiol. 275:C711-C731.

3. Witzgall, R., Brown, D., Schwarz, C., and Bonventre, J.V. 1994. Localization of proliferating cell nuclear antigen, vimentin, c-Fos, and clusterin in the postischemic kidney. Evidence for a heterogenous genetic response among nephron segments, and a large pool of mitotically active and dedifferentiated cells. J. Clin. Invest. 93:2175-2188.

4. Witzgall, R., et al. 1998. Kid-1 expression is high in differentiated renal proximal tubule cells and suppressed in cyst epithelia. Am. J. Physiol. 275:F928-F937.

5. Sutton, T.A., Fisher, C.J., and Molitoris, B.A. 2002. Microvascular endothelial injury and dysfunction during ischemic acute renal failure. Kidney Int. 62:1539-1549.

6. Conger, J., Robinette, J., Villar, A., Raij, L., and Shultz, P. 1995. Increased nitric oxide synthase activity despite lack of response to endotheliumdependent vasodilators in postischemic acute renal failure in rats. J. Clin. Invest. 96:631-638.

7. Baddoo, M., et al. 2003. Characterization of mesenchymal stem cells isolated from murine bone marrow by negative selection. J. Cell. Biochem. 89:1235-1249.

8. Pittenger, M.F., et al. 1999. Multilineage potential of adult human mesenchymal stem cells. Science. 284:143-147.

9. Ferrari, G., et al. 1998. Muscle regeneration by bone marrow-derived myogenic progenitors. Science. 279:1528-1530.

10. Jackson, K.A., et al. 2001. Regeneration of ischemic cardiac muscle and vascular endothelium by adult stem cells. J. Clin. Invest. 107:1395-1402.

11. Orlic, D., et al. 2001. Mobilized bone marrow cells repair the infarcted heart, improving function and survival. Proc. Natl. Acad. Sci. U. S. A. 98:10344-10349.

12. Krause, D.S., et al. 2001. Multi-organ, multi-lineage engraftment by a single bone marrow-derived stem cell. Cell. 105:369-377.

13. Lagasse, E., et al. 2000. Purified hematopoietic stem cells can differentiate into hepatocytes in vivo. Nat. Med. 6:1229-1234.

14. Poulsom, R., et al. 2001. Bone marrow contributes to renal parenchymal turnover and regeneration. J. Pathol. 195:229-235.

15. Kale, S., et al. 2003. Bone marrow stem cells contribute to repair of the ischemically injured renal tubule. J. Clin. Invest. 112:42-49. doi:10.1172/ JCI200317856.

16. Lin, F., et al. 2003. Hematopoietic stem cells contribute to the regeneration of renal tubules after renal ischemia-reperfusion injury in mice. J. Am. Soc. Nephrol. 14:1188-1199.

17. Morigi, M., et al. 2004. Mesenchymal stem cells are renotropic, helping to repair the kidney and improve function in acute renal failure. J. Am. Soc. Nephrol. 15:1794-1804.

18. Park, K.M., Kramers, C., Vayssier-Taussat, M., Chen, A., and Bonventre, J.V. 2002. Prevention of kidney ischemia/reperfusion-induced functional injury, MAPK and MAPK kinase activation, and inflammation by remote transient ureteral obstruction. J. Biol. Chem. 277:2040-2049.

19. Okabe, M., Ikawa, M., Kominami, K., Nakanishi, T., and Nishimune, Y. 1997. 'Green mice' as a source of ubiquitous green cells. FEBS Lett. 407:313-319.

20. Ahern-Rindell, A.J., Murnane, R.D., and Prieur, D.J. 1988. Beta-galactosidase activity in fibroblasts and tissues from sheep with a lysosomal storage disease. Biochem. Genet. 26:733-746.

21. Weiss, D.J., Liggitt, D., and Clark, J.G. 1999. Histochemical discrimination of endogenous mammalian beta-galactosidase activity from that resulting from lac-Z gene expression. Histochem. J. 31:231-236.

22. Prockop, D.J., et al. 2000. Potential use of stem cells from bone marrow to repair the extracellular matrix and the central nervous system. Biochem. Soc. Trans. 28:341-345.

23. Peister, A., et al. 2004. Adult stem cells from bone marrow (MSCs) isolated from different strains of inbred mice vary in surface epitopes, rates of proliferation, and differentiation potential. Blood. 103:1662-1668.

24. Yamamoto, Y., et al. 1996. Characterization of peripheral blood stem cells in mice. Blood. 88:445-454.

25. Camargo, F.D., Finegold, M., and Goodell, M.A. 2004. Hematopoietic myelomonocytic cells are the major source of hepatocyte fusion partners. J. Clin. Invest. 113:1266-1270. doi:10.1172/JCI200421301.

26. Sheridan, A.M., and Bonventre, J.V. 2000. Cell biology and molecular mechanisms of injury in ischemic acute renal failure. Curr. Opin. Nephrol. Hypertens. 9:427-434

27. Spyridonidis, A., et al. 2004. Epithelial tissue chimerism after human hematopoietic cell transplantation is a real phenomenon. Am. J. Pathol. 164:1147-1155.

28. Wagers, A.J., Sherwood, R.I., Christensen, J.L., and Weissman, I.L. 2002. Little evidence for developmental plasticity of adult hematopoietic stem cells. Science. 297:2256-2259.

29. Theise, N.D., et al. 2000. Derivation of hepatocytes from bone marrow cells in mice after radiationinduced myeloablation. Hepatology. 31:235-240.

30. Orlic, D., et al. 2001. Bone marrow cells regenerate infarcted myocardium. Nature. 410:701-705

31. Brazelton, T.R., Rossi, F.M., Keshet, G.I., and Blau, H.M. 2000. From marrow to brain: expression of neuronal phenotypes in adult mice. Science. 290:1775-1779.

32. Mathews, V., et al. 2004. Recruitment of bone marrow-derived endothelial cells to sites of pancreatic beta-cell injury. Diabetes. 53:91-98.

33. Asano, G., et al. 2003. Pathogenesis and protection of ischemia and reperfusion injury in myocardium. J. Nippon Med. Sch. 70:384-392.

34. Bittmann, I., Hentrich, M., Bise, K., Kolb, H.J., and Lohrs, U. 2003. Endothelial cells but not epithelial cells or cardiomyocytes are partially replaced by donor cells after allogeneic bone marrow and stem cell transplantation. J. Hematother. Stem Cell Res. 12:359-366. 
35. Hu, Y., Davison, F., Zhang, Z., and Xu, Q. 2003. Endothelial replacement and angiogenesis in arteriosclerotic lesions of allografts are contributed by circulating progenitor cells. Circulation. 108:3122-3127.

36. Lagaaij, E.L., et al. 2001. Endothelial cell chimerism after renal transplantation and vascular rejection. Lancet. 357:33-37.

37. Arriero, M., Brodsky, S.V., Gealekman, O., Lucas, P.A., and Goligorsky, M.S. 2004. Adult skeletal muscle stem cells differentiate into endothelial lineage and ameliorate renal dysfunction after acute ischemia. Am. J. Physiol. Renal Physiol. 287:F621-F627.

38. Brodsky, S.V., et al. 2002. Endothelial dysfunction in ischemic acute renal failure: rescue by transplanted endothelial cells. Am. J. Physiol. Renal Physiol. 282:F1140-F1149.

39. Basile, D.P., Donohoe, D., Roethe, K., and Osborn, J.L. 2001. Renal ischemic injury results in permanent damage to peritubular capillaries and influences long-term function. Am. J. Physiol. Renal Physiol. 281:F887-F899.

40. Bompais, H., et al. 2004. Human endothelial cells derived from circulating progenitors display specific functional properties compared with mature vessel wall endothelial cells. Blood. 103:2577-2584.

41. Asahara, T., et al. 1997. Isolation of putative progenitor endothelial cells for angiogenesis. Science. 275:964-967.

42. Li, T.S., et al. 2003. CD117+ stem cells play a key role in therapeutic angiogenesis induced by bone marrow cell implantation. Am. J. Physiol. Heart Circ. Physiol. 285:H931-H937.
43. Fujiyama, S., et al. 2003. Bone marrow monocyte lineage cells adhere on injured endothelium in a monocyte chemoattractant protein-1-dependent manner and accelerate reendothelialization as endothelial progenitor cells. Circ. Res. 93:980-989.

44. Annabi, B., Naud, E., Lee, Y.T., Eliopoulos, N., and Galipeau, J. 2004. Vascular progenitors derived from murine bone marrow stromal cells are regulated by fibroblast growth factor and are avidly recruited by vascularizing tumors. J. Cell. Biochem. 91:1146-1158.

45. Bailey, A.S., et al. 2004. Transplanted adult hematopoietic stems cells differentiate into functional endothelial cells. Blood. 103:13-19.

46. Prockop, D.J. 1997. Marrow stromal cells as stem cells for non-hematopoietic tissues. Science. 276:71-74.

47. Gao, Y., Herndon, J.M., Zhang, H., Griffith, T.S., and Ferguson, T.A. 1998. Antiinflammatory effects of CD95 ligand (FasL)-induced apoptosis. J. Exp. Med. 188:887-896.

48. Morelli, A.E., et al. 2003. Internalization of circulating apoptotic cells by splenic marginal zone dendritic cells: dependence on complement receptors and effect on cytokine production. Blood. 101:611-620.

49. Balsam, L.B., et al. 2004. Haematopoietic stem cells adopt mature haematopoietic fates in ischaemic myocardium. Nature. 428:668-673.

50. Dor, Y., Brown, J., Martinez, O.I., and Melton, D.A. 2004. Adult pancreatic beta cells are formed by selfduplication rather than stem cell differentiation. Nature. 429:41-46.

51. Wagers, A.J., and Weissman, I.L. 2004. Plasticity of adult stem cells. Cell. 116:639-648.
52. Bonventre, J.V. 2003. Dedifferentiation and proliferation of surviving epithelial cells in acute renal failure. J. Am. Soc. Nephrol. 14(Suppl. 1):S55-S61.

53. Hocht-Zeisberg, E., et al. 2004. Cellular repopulation of myocardial infarction in patients with sexmismatched heart transplantation. Eur. Heart J. 25:749-758.

54. Iwatani, H., et al. 2004. Hematopoietic and nonhematopoietic potentials of Hoechst/side population cells isolated from adult rat kidney. Kidney Int. 65:1604-1614.

55. Oliver, J.A., Maarouf, O., Cheema, F.H., Martens, T.P., and Al-Awqati, Q. 2004. The renal papilla is a niche for adult kidney stem cells. J. Clin. Invest. 114:795-804. doi:10.1172/JCI200420921.

56. Park, K.M., Kim, J.I., Ahn, Y., Bonventre, A.J., and Bonventre, J.V. 2004. Testosterone is responsible for enhanced susceptibility of males to ischemic renal injury. J. Biol. Chem. 279:52282-52292.

57. Park, K.M., et al. 2003. Inducible nitric-oxide synthase is an important contributor to prolonged protective effects of ischemic preconditioning in the mouse kidney. J. Biol. Chem. 278:27256-27266.

58. Bonventre, J.V., and Witzgall, R. 1995. Kid-1, a kidney transcription factor. Exp. Nephrol. 3:159-164.

59. Bhan, A.K., et al. 1985. Studies with monoclonal antibodies against brush border antigens in Heymann nephritis. Lab. Invest. 53:421-432.

60. Duffield, J.S., et al. 2000. Activated macrophages direct apoptosis and suppress mitosis of mesangial cells. J. Immunol. 164:2110-2119.

61. Stuart, L.M., et al. 2002. Inhibitory effects of apoptotic cell ingestion upon endotoxin-driven myeloid dendritic cell maturation. J. Immunol. 168:1627-1635. 